\title{
Rational clinical use of blood and blood products - A summary
}

\section{Ghartimagar $\mathrm{D}^{1}$}

${ }^{I}$ Department of Pathology, Manipal College of Medical Sciences, Manipal Teaching Hospital, Pokhara, Nepal.

\section{Keywords:}

Blood;

Blood components;

Rational;

Transfusion

\begin{abstract}
Blood transfusion is an essential therapeutic intervention. The main role of the blood centre is to provide safe and timely blood and blood component(s) to the patients that will improve the physiological status of the patient. Various blood components can be harvested from a single donation of whole blood. The blood centre ensures that there is an adequate inventory of all blood types and blood components to meet the needs of the patients. The blood centre does donor selection, blood collection, component preparation, screening for transfusion - transmitted infections and blood processing. Serologically compatible blood and components are provided to the patients after meticulous pre-transfusion testing as per the standard protocol. Rational use of blood and blood products means right product is used with the right dose on right time for the right reason.
\end{abstract}

\section{INTRODUCTION}

Blood transfusion is an essential therapeutic intervention. We all may need blood in an emergency, and some of us need regular transfusions. The purpose of a transfusion is to provide the blood component(s) that will improve the physiological status of the patient. Various blood components can be harvested from a single donation of whole blood. In our part of the world, increasing numbers of blood banks are able to separate red cells and plasma components while a few are able to prepare components

\section{Correspondence:}

Dr. Dilashma Ghartimagar, MBBS,MD

Associate Professor, Department of Pathology,Manipal College of Medical Sciences Pokhara, Nepal.

Email:dilasmagm@hotmail.com such as platelet concentrates and cryoprecipitate. ${ }^{1}$ This topic mainly focuses on the clinical aspects of blood transfusion and aims to show how unnecessary transfusions can be reduced at all levels of the health care system without compromising standards of quality and safety.

\section{Appropriate use of blood and blood products}

1. The appropriate use of blood and blood products means the transfusion of safe blood products only to treat a condition leading to significant morbidity or mortality that cannot be prevented or managed effectively by other means.

2. Transfusion carries the risk of adverse reactions and transfusion transmissible infections. Plasma can transmit 
most of the infections present in whole blood and there are very few indications for its transfusion.

3. Blood donated by family/replacement donors carries a higher risk of transfusion-transmissible infections than blood donated by voluntary non-remunerated donors. Paid blood donors generally have the highest incidence and prevalence of transfusion-transmissible infections.

4. Blood should not be transfused unless it has been obtained from appropriately selected donors, has been screened for transfusion transmissible infections and tested for compatibility between the donor's red cells and the antibodies in the patient's plasma. ${ }^{2}$

\section{Screening}

The screening of all donated blood is done for transfusiontransmissible infections like HIV I and II, hepatitis viruses B and $\mathrm{C}$, syphilis and, wherever appropriate, other infectious agents, such as malaria and Chagas disease.

\section{Collection and storage}

The collection of blood from donors may take place within the blood transfusion centres or hospitals blood banks. It is also often collected from donors during mobile blood collection sessions. The blood is then taken to a laboratory for testing and processing into components and for storage and distribution as the need arises..$^{3,4}$

Blood is collected at body temperature, i.e. $+37{ }^{\circ} \mathrm{C}$. Inorder to maintain its vital properties, it must be cooled to below $+10^{\circ} \mathrm{C}$ to be transported, and stored at refrigeration temperatures of around $+4{ }^{\circ} \mathrm{C}$ until use. Hence the term, blood cold chain, which begins the moment the blood is collected and continues until it is transfused. If blood is stored or transported outside of these temperatures for long, it loses its ability to transport oxygen or carbon dioxide to and from tissues respectively upon transfusion. Other factors of serious concern are the risk of bacterial contamination if blood is exposed to warm temperatures. Conversely, blood exposed to temperatures below freezing may be damaged, and the transfusion of such blood can be fatal. ${ }^{3}$

Whole blood and red cells must always be stored at a temperature between $+2{ }^{\circ} \mathrm{C}$ and $+6{ }^{\circ} \mathrm{C}$. The main reasons for giving a blood transfusion are to restore or help to maintain the body's oxygen-carrying capacity in the body. If blood is not stored at between $+2{ }^{\circ} \mathrm{C}$ and $+6{ }^{\circ} \mathrm{C}$, its oxygen-carrying ability is greatly reduced. If blood is stored above $+6{ }^{\circ} \mathrm{C}$, bacteria that may have inadvertently entered the unit during collection may grow to such an extent that transfusion of the contaminated blood could be fatal. The lower limit of $+2{ }^{\circ} \mathrm{C}$ is also very important. This is because red cells are very sensitive to freezing. If they are allowed to freeze, the red cell membranes rupture and the haemoglobin is released or the cells are haemolysed. The transfusion of haemolysed blood can be fatal. ${ }^{5}$

The anticoagulant/preservative solution in the blood bag contains nutrients for the blood during storage and stops the blood from clotting. The red cells can only carry and deliver oxygen if they remain viable. The most important substances in maintaining the viability of red cells are glucose and adenosine triphosphate (ATP). It is essential to maintain an equilibrium between ATP, 2,3 Diphosphoglycerate (2,3 DPG), glucose and pH. One of the anticoagulant/ preservatives most commonly used is citrate phosphate dextrose with adenine (CPDA-1). The dextrose and adenine help the red cells to maintain ATP during storage, and the citrate is the anticoagulant which stops the blood from clotting. $^{2}$

\section{General Guidelines}

\section{Check the blood or components before starting the transfusion.}

- Check the physician's order to verify that you have received the required blood or component ordered.

- Match ABO and Rh group of the patient with the ABO \& $\mathrm{Rh}$ group of the blood product label. If there is discrepancy, do not start transfusion. Report to the blood center immediately.

- Check expiration date, unit number, component label, and special process label such as irradiated.

- Compare the blood bag number with the number listed on compatibility report. ${ }^{4,6}$

\section{Identification of the Patient:}

- This is a very important step before starting the transfusion, as misidentification of the patient is the most common cause of mismatched transfusion and prove fatal to the patient.

- Compare the patient name, hospital number and blood group on the blood bag with the patient name and hospital number and blood group on the patient file.

- Before starting the transfusion, record the time, temperature of the patient, pulse rate and BP on the patient file. This will be helpful to monitor any changes in the vitals during transfusion. ${ }^{4,7,8}$

\section{Administration of red blood cell components:}

- Ensure the IV line is patent and Gauge of the needle is adequate to transfuse the blood component. Use a standard blood transfusion set with filter. ${ }^{4}$ 


\section{Concurrent fluids along with red cell transfusion:}

- Avoid additions of any type of fluid or drug into the blood bag.

- Only compatible IV solutions, such as isotonic (0.9\%) saline may be used along with red cell transfusion.

- Do not mix any medication along with red cell unit. Some drugs can cause hemolysis due to their high pH. 5\% dextrose can cause agglutination of red blood cells. Lactate ringer solution can result in clotting because of its calcium content. If medication were added to the blood component it would be difficult to investigate the cause of the transfusion reaction if there is any.

- Do not mix blood components together, e.g. red cells and platelets before transfusion.

\section{Transfusion process:}

- Start the transfusion slowly for first 15 minutes and observe the patient. If the clinical status is normal, remaining unit can be transfused as per the indication. However, check the patient frequently for any significant change in the vitals.

- Red Cell transfusion should be completed within 4 hours of starting. Beyond 4 hours, there is a risk of bacterial contamination.

The goal of transfusion therapy is to correct an abnormality that will not respond to other modes of treatment to provide a patient with life support when safer alternatives are not possible. $^{5}$

\section{BLOOD \& BLOOD COMPONENTS}

Other than whole blood, various components that are available in the Blood Center for clinical use include:

\section{- Oxygen carrying components o Red cell concentrate o Red cell suspension o Leucocyte depleted red cells \\ o Irradiated red cells \\ - Platelet Products: \\ o Single donor platelet concentrate (PC - Apheresis). \\ o Random donor platelet concentrate}

- Plasma Product:
o Fresh Frozen Plasma (FFP)
o Cryoprecipitate
o Cryo poor plasma
o Others - albumin, coagulation factors, immunoglobulins.

\section{WHOLE BLOOD}

Whole blood is the unseparated blood collected into an approved container containing an anticoagulantpreservative solution.

\section{Indications:}

- Red cell replacement in acute blood loss with hypovolaemia- trauma and shock.

- Exchange transfusion.

- Patients needing red cell transfusions where red cell concentrates or suspensions are not available.

\section{Contraindications:}

- Risk of volume overload in patients with o Chronic anaemia o Incipient cardiac failure

\section{Administration:}

- Must be $\mathrm{ABO}$ and $\mathrm{RhD}$ compatible with the recipient.

- Never add medication to a unit of blood.

- Complete transfusion within 4 hours of commencement.

\section{RED CELL CONCENTRATE}

Red Blood cells are the cellular product obtained after centrifugation of whole blood and removal of most of the plasma. The usual unit of red cell concentrate should raise Hct or $\mathrm{Hb}$ by approximately $3 \%$ or $1 \mathrm{gm} \%$ respectively in an average adult patient and $3 \mathrm{gm} \% \mathrm{Hb}$ in infants.

\section{Indications:}

- Replacement of red cells in anaemic patients. - Use with crystalloid replacement fluids or colloid solution in acute blood loss.

\section{Administration:}

- Must be $\mathrm{ABO}$ and $\mathrm{RhD}$ compatible with the recipient.

- To improve transfusion flow, normal saline (50-100 ml) may be added using a Y-pattern infusion set.

\section{RED CELL SUSPENSION}

\section{Indications:}

- Replacement of red cells in anaemic patients.

- Use with crystalloid replacement fluids or colloid solution in acute blood loss.

\section{Contraindications:}


- Not advised for exchange transfusion of neonates.

\section{Administration:}

- Must be $\mathrm{ABO}$ and $\mathrm{RhD}$ compatible with the recipient - To improve transfusion flow, normal saline (50-100 ml) may be added.

\section{LEUCOCYTE-DEPLETED RED CELLS}

Leukocytes in blood products can induce adverse effects during transfusion, primarily febrile, non-hemolytic reactions.

\section{Indications:}

- Patients receiving repeated transfusions. - Immune suppressed patients - reduces risk of CMV transmission, since CMV lives in WBCs. - Patients who have experienced two or more previous febrile reactions to red cell transfusion. - Present thinking attributes reactions to cytokines produced by leukocytes in transfused units. - Other explanations to reactions include: immunization of recipient to transfused HLA or granulocyte antigens, micro aggregates and fragmentation of granulocytes.

\section{Contraindications:}

- Will not prevent graft-vs-host disease (GVHD). For this purpose, blood components should be irradiated where facilities are available (radiation dose: 25-30 Gy).

\section{Administration:}

- Must be $\mathrm{ABO}$ and $\mathrm{RhD}$ compatible with the recipient. - A leucocyte filter may also be used at the time of transfusion if leucocyte-depleted red cells or whole blood are not available.

\section{IRRADIATED BLOOD PRODUCTS}

Blood components that contain viable lymphocytes may be irradiated to prevent proliferation of $\mathrm{T}$ lymphocytes, which is the immediate cause of Transfusion-Associated GVHD (TA-GVHD). In order to minimize the risk of TA- GVHD in susceptible individuals, cellular blood products (packed red blood cells, platelets) should be irradiated to a dose of 25 Gy prior to transfusion. Blood must be labelled "irradiated".

\section{Indications:}

o Patients undergoing bone marrow or peripheral blood stem cell transplantation.

o Patients with Hodgkins lymphoma.

o Patients with congenital immunodeficiency syndrome. o Intra-uterine transfusion.

\section{Side Effects and Hazards:}

Irradiation induces erythrocyte membrane damage. Irradiated red cells have been shown to have higher supernatant potassium levels than non-irradiated red cells. Removal of residual supernatant plasma before transfusion may reduce the risks associated with elevated plasma potassium. The expiration date of irradiated red cells is changed to 28 days after irradiation. ${ }^{2}$

\section{PLATELET CONCENTRATE}

There are two types of platelet concentrate (PC) available, random donor PC or single donor PC (collected by apheresis)

\section{Random Donor PC (prepared from whole blood donations):}

Each unit of PC is prepared from a unit of whole blood by centrifugation within 8 hours of phlebotomy. Can be stored upto 72 hours at $20^{\circ} \mathrm{C}$ to $24^{\circ} \mathrm{C}$ (with agitation) unless collected in specialized platelet packs validated for longer storage periods; do not store at $2^{\circ} \mathrm{C}$ to $6^{\circ} \mathrm{C}$. Agitation is essential to prevent platelet aggregation which results in loss of viability.

\section{Indications:}

- Treatment of bleeding due to:

— Thrombocytopenia

— Platelet function defects

- Prevention of bleeding due to thrombocytopenia, such as in bone marrow failure

\section{Contraindications:}

- Idiopathic autoimmune thrombocytopenic purpura (ITP).

- Thrombotic thrombocytopenic purpura (TTP).

- Untreated disseminated intravascular coagulation (DIC).

- Thrombocytopenia associated with septicaemia, until treatment has commenced or in cases of hypersplenism.

\section{Administration:}

- After pooling, platelet concentrates should be infused as soon as possible, generally within 4 hours, because of the risk of bacterial proliferation.

- 4-6 units of platelet concentrates (which may be supplied pooled) should be infused through a fresh standard blood administration set. 
- Do not give platelet concentrates prepared from $\mathrm{RhD}$ positive donors to an $\mathrm{RhD}$ negative female with childbearing potential.

- Give platelet concentrates that are ABO compatible, whenever possible.

\section{Single donor platelet concentrate (PC- apheresis)}

This component is collected from an individual donor with the help of apheresis machines (cell separators). A single unit of apheresis PC contains 3-5X10 11 platelets / unit and is suspended in 200 to $300 \mathrm{ml}$ of autologous plasma. Therefore, one unit of apheresis PC is equivalent to approximately 6 units of random donor PC. It is especially useful for patients who are likely to receive long term platelet support such as aplastic anemia or bone marrow transplantation recipients as the number of donor exposures is decreased considerably. One unit of apheresis PC raises the platelet count by 30,000 /ul in adult patient.

Storage: Can be stored upto 72 hours at $20^{\circ} \mathrm{C}$ to $24^{\circ} \mathrm{C}$ (with agitation) unless collected in specialized platelet packs validated for longer storage periods; do not store at $2^{\circ} \mathrm{C}$ to $6^{\circ} \mathrm{C}$.

\section{Indications:}

- Generally equivalent to the same dose of platelet concentrates prepared from whole blood.

- If a specially typed, compatible donor is required for the patient, several doses may be obtained from the selected donor.

\section{Contraindications:}

- Patients with thrombotic thrombocytopenic purpura. - Patients with ITP unless there is life threatening bleeding or intracranial hemorrhage.

\section{Dosage:}

- One pack of platelet concentrate collected from a single donor by apheresis is usually equivalent to 1 therapeutic dose.

\section{Administration:}

- $\mathrm{ABO}$ compatibility is more important as high titre anti-A or anti-B in the donor plasma used to suspend the platelets may cause haemolysis of the recipient's red cells.

\section{FRESH FROZEN PLASMA}

Fresh frozen plasma (FFP) is plasma that has been separated from a unit of whole blood within 6 to 8 hours of collection, and has been rapidly frozen and maintained at all times at a temperature of $-25^{\circ} \mathrm{C}$ or lower which can be stored for up to 1 year. Plasma contains water, electrolytes, clotting factors and other proteins (mostly albumin). FFP may be given to a patient to restore or help to maintain coagulation factors such as Factor V or Factor VIII. Plasma should not be used as a volume expander unless crystalloids and colloids are unavailable.

FFP is indicated in the control or prevention of bleeding in patients with multiple coagulation factor defects. FFP must be thawed at $37^{\circ} \mathrm{C}$ in a water bath with due precautions. They can be kept at $4^{\circ} \mathrm{C}$ for not more than $4 \mathrm{hrs}$. FFP should be used as soon as it is thawed to avoid the degeneration of clotting factors.

\section{Indications:}

- Broad spectrum coagulation factor deficiency.

- Severe liver disease.

- Oral anticoagulant overdose.

- Disseminated intravascular coagulation (DIC).

- Massive transfusion with coagulation problems.

- Thrombotic thrombocytopenic purpura (TTP).

- Anti-Thrombin III deficiency.

\section{Precautions:}

- Acute allergic reactions are not uncommon, especially with rapid infusions.

- Severe life-threatening anaphylactic reactions occasionally occur.

- Hypovolaemia alone is not an indication for use.

\section{Administration:}

- Must normally be ABO compatible to avoid risk of haemolysis in recipient.

- No compatibility testing required.

\section{CRYOPRECIPITATE}

Cryoprecipitate is the cold insoluble precipitate having Factor VIII, vWF, fibrinogen and factor XIII as its major constituents. Standards require an average of 80 IU of F VIII in each unit. At $-25^{\circ} \mathrm{C}$ or colder temperature, it can be stored for up to 1 year. Thawed cryoprecipitate should be store at $4^{\circ} \mathrm{C}$ and used within 4 hours.

\section{Indications:}

- Factor VIII Deficiency (Hemophilia A): The treatment of choice is virus inactivated factor VIII concentrates which is provided by the department for the treatment of hemophilia patients

- Von Willebrand's Disease 
- Hypofibrinogenemia ( $<80 \mathrm{mg} / \mathrm{dl})$ :

o Consumptive coagulopathy ( DIC),

o Dysfibrinogenemia or Afibrinogenemia.

\section{Administration:}

- If possible, use $\mathrm{ABO}$-compatible product.

- No compatibility testing required.

- After thawing, infuse as soon as possible through a

standard blood administration set.

- Must be infused within 6 hours of thawing.

Factors VIII and IX and immunoglobulins are also made by recombinant DNA technology and are often favoured because there is no risk of transmitting infectious agents to the patient; however, the costs are high. ${ }^{3,5,9}$

\section{PLASMA DERIVATIVES}

Unlike blood components, plasma derivatives such as albumin or immunoglobulin are concentrated, sterile specific proteins, obtained from large pools of donor plasma. They are used to treat patients with specific protein deficiencies or requirements for passive immunity.

Human plasma proteins prepared under pharmaceutical manufacturing conditions, such as:

- Albumin

- Coagulation factor concentrates

- Immunoglobulins ${ }^{10}$

\section{WARMING OF BLOOD PRODUCTS}

Generally, there is no need to warm the unit of red cells before transfusion. Keeping the blood unit at room temperature for 30 minutes will be enough in most cases. Patients who will benefit from warmed blood include adults and children receiving massive transfusion, ${ }^{11}$ infants requiring exchange transfusion and patients with cold agglutinins in the serum, it is important to pre warm the unit at $37^{\circ} \mathrm{C}$ before transfusion. Special blood warmers may be used for this purpose. Blood should not be warmed in Dry Incubator in the laboratory. It is important to keep the patient warm during transfusion. Always check for the presence of hemolysis while using a blood warmer. Red blood cells and plasma exposed to temperatures over $40^{\circ} \mathrm{C}$ may cause severe transfusion reactions. ${ }^{6}$

\section{GRANULOCYTES}

Prepared by hemapheresis and stored at $20-24^{\circ} \mathrm{C}$. Expiration time is 24 hours but best to infuse as early as possible.

- Primary use is for patients with neutropenia who have gram negative infections documented by culture, but are unresponsive to antibiotics.

\section{- Daily transfusions are necessary.}

Better antimicrobial agents and use of granulocyte and macrophage colony stimulating factors best for adults, best success with this component has been with babies. Therapeutic efficacy and indications for granulocyte transfusions are not well defined. ${ }^{2}$

\section{WASHING}

Washed components are typically prepared using $0.9 \%$ Sodium Chloride, Injection (USP) with or without small amounts of dextrose. Washing of blood components is indicated to remove unwanted plasma when it contains constituents that predispose patients to significant transfusion reactions (eg, the removal of IgA-containing plasma in providing transfusion support for an IgA-deficient recipient or in rare recipients experiencing anaphylactoid reactions to plasma components). There will also be some loss of red cells and platelets, as well as a loss of platelet function through platelet activation. The shelf life of washed components is no more than 24 hours at 1 to $6^{\circ} \mathrm{C}$ or 4 hours at 20 to $24^{\circ} \mathrm{C}>$ Therefore washing is not a substitute for leukocyte reduction.

\section{Specific Washed Components}

- Washed red blood cells (red blood cells washed) - Washed apheresis red blood cells (red blood cells pheresis washed) washed platelets (platelets washed) - Washed apheresis platelets (platelets pheresis washed) ${ }^{10}$

\section{CONCLUSION}

The rational use of blood and blood products means the right blood goes to the right patient at the right time. Patients seldom require all of the components of whole blood so, it should be separated into units of red cells, plasma and platelets before it reaches a patient. Once the decision to transfuse has been made, everyone involved in the blood banking as well as in transfusion process has the responsibility for the transfusion of safe blood products.

\section{ACKNOWLEDGMENTS}

I would like to thank Dr. Arnab Ghosh and others in Dept of Pathology, MCOMS for their support and help while writing this review article.

\section{REFERENCES}

1. Safe blood and blood products. WHO, Manual on the management, maintenance and use of blood cold chain equipment. World Health Organization. Geneva

2. The Clinical Use of Blood. WHO, Handbook World Health Organization Blood Transfusion Safety. GENEVA

3. American Association of Blood Banks (AABB) Technical Manual, 


\section{3th Edition}

4. Blood Transfusion Manual. Department of Transfusion Medicine SGPGIMS, Lucknow

5. Safe Blood and Blood Products. Distance Learning Materials. Revised Edition. WHO, Marketing \& Dissemination, 1211 Geneva 27, Switzerland. ISBN 924154546 1. Order No. 1150490.2002

6. McClelland DBL. (editor) Handbook of Transfusion Medicine, 3rd Edition. London: The Stationery Office, 2001.

7. Cummins D, Sharp S, Vartanian M, Dawson D, Amin S, and Halil $\mathrm{O}$. The BCSH guideline on addressograph labels: experience at a cardiothoracic unit and findings of a telephone survey. Transfusion Medicine 2000;10:117-120. Crossref
8. Brecher ME. (editor) American Association of Blood Banks Technical Manual, 14th Edition. Bethesda, MD: AABB Press, 2002.

9. Guidelines for the Administration of Blood and Blood Components. Issued by the National Blood Users Group 2004. National Haemovigilance Office. Dublin: Irish Blood Transfusion Service.

10. Circular of information. For the use of human blood and blood components. AABB, the American Red Cross, America's Blood Centers, and the Armed Services Blood Program, August 2009.

11. National Blood Users Group (NBUG). A Guideline for the Use of Blood Components in the Management of Massive Haemorrhage. Dublin: Irish Blood Transfusion Service, 2004. 